\title{
Kleine Mittheilungen.
}

Hatten die Franken ein Ordal des Flammengriffs? Einige Stellen der Lex Ribuar. 1) haben zu der Vermuthung Anlass gegeben, dass das fränkische Recht eine von der sonst üblichen Art abweichende Form des Feuerordals besessen habe, den Flammengriff, darin bestehend, dass der Beweisführer die Hand in ein Feuer habe halten müssen, um aus ihrer etwaigen Verletzung seine Schuld zu constatiren. Diese, zuerst wohl von Grimm ${ }^{2}$ ) aufgestellte Theorie, ist von zahlreichen Gelehrten acceptirt worden ${ }^{3}$ ). Widerspruch hat sich dagegen erst in neuerer Zeit erhoben, ausdrücklich von Zeumer ${ }^{4}$ ) und Brunner ${ }^{5}$ ), während Schroeder ${ }^{6}$ ) seine Missbilligung durch vollständiges Schweigen über ein solches Ordal zu erkennen giebt. Entscheidend ist für die Controverse, welche Bedeutung in den citirten Gesetzesstellen dem Wort igneum zu geben ist, ob wir darunter thatsächlieh ignis oder eine Nebenform von aeneum, dem bei der sonst üblichen Feuerprobe verwendeten Kessel, zu verstehen haben. Dass letateres zutrifft, dafür hat Brunner ${ }^{7}$ ) bereits unter Heranziehung mehrerer Novellen zum salischen Gesetz den Nachweis erbracht. Es dürfte sich aber auch noch aus andern Gründen die Unzulässigkeit der entgegengesetzten Annahme darthun lassen.

Zunächst ist auffallend, was freilich auch schon von Brunner

1) $30,1,2.31,5 . \quad$ 2) Rechtsalterthümer 912.

3) Wilda, Ordalien (bei Ersch und Gruber) 455. Siegel, Geschichte des deutschen Gerichtsverfahrens 237. Dahn, Studien zur Geschichte der germanischen Gottesurtheile 43. Sohm in den Anmerkungen zu den zitirten Bestimmungen der 1. Rib. Glasson, Histoire du droit et des institutions de la France 3, 504.

4) Im Index rerum et verborum znr l. Rib. et Chav. s. m. igneum und ignis.

5) Deutsche Rechtsgeschichte 2, 407.

B) Deutsche Rechtsgeschichte 2. Auf. 357 t. $\quad$ 7) l. c. 
betont wurde, dass uns kein einziger Anwendungsfall dieses angeblichen Ordals überliefert ist. Dahn ${ }^{1}$ ) verweist allerdings auf eine Stelle des Gregor von Tours 2), die jedoch ganz beweislos ist. Es handelt sich dort um einen religiösen Streit eines Ketzers und eines Orthodoxen, in dessen Verlauf der Rechtgläubige, um seinen Gegner auch durch ein Wunder von der Wahrheit seiner Behauptungen zu überzengen, seinen Ring in ein Feuer wirft, und ihn dann, ohne sich zu verletzen, aus den Flammen herausholt und glühend in der Hand hält. Das wesentliche ist hier das Herausnehmen und Haiten des glühenden Gegenstandes, nicht das Hineingreifen in die Flamme. Auch wäre aus einem so gelegentlichen Vorgang der Schluss noch nicht erlaubt, dass dabei ein auch sonst zur Anwendung gekommenes Ordal vorliege. Ueber den Flammengriff schweigen sich ferner die Formulare für die Gottesurtheile völlig aus, die sonst für jedes Ordal mannigfache Muster überliefern.

Der Flammengriff ist ferner den übrigen arischen Völkern unbe-

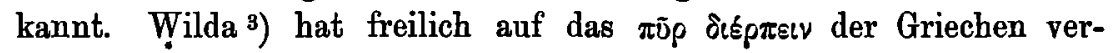
wiesen, das sich auch bei Iren und Indern findet ${ }^{4}$ ), und auch in sagenhaften Berichten des späteren Mittelalters erwähnt wird 5). Allein Flammendurchschreiten und Flammengriff sind zwei begrifflich ganz verschiedene Ordale. Weil das eine bei den Franken verwandten Völkern üblich, ist noch nicht anzunehmen, dass nunmehr auch das andere bei ihnen selbst gegolten haben müsse.

Am stärksten dürfte jedoch gegen die Existenz des Flammengriffs sprechen, dass eine die Ordalien aufzählende Quelle der fränkischen Zeit dieses Gottesurtheils gar nicht gedenkt. Es ist dies die Streitschrift des Bischofs Agobard von Lyon: Liber de divinis sententiis digestus u. s. w. ${ }^{6}$ ) Nachdem Agobard bereits in einem früheren, sich wesentlich gegen die Gundobada richtenden Werk das Ordal des Zweikampfs angegriffen hatte ${ }^{7}$ ), wendet er sich in dieser zweiten Arbeit gegen die Gottesurtheile überhaupt, die er jedoch nur bekämpft, soweit sie sich nicht auf kirchliche Unterstützung berufen konnten. Denn dass er die Gottesurtheile nicht in Bausch und Bogen verwarf, lehren die einleitenden Worte seiner Schrift, in denen er als allein zulässige Beweismittel Zeugen und Eid, dann aber auch den Trank des bittern Wassers aufführt ${ }^{8}$ ), den nach der Vorschrift des alten Testaments die des Ehebruchs beschuldigte Frau einzunehmen hatte,

1) 43 2) De gloria confessorum cp. 14. Irrthümlich auch bei Schroeder 357 Anmerk. 51 zitirt. 3) 459 .

6) Opera. ed. Mass. 1605, 287 f.

7) Ad imperatorem de duello $103 \mathrm{f} . \quad$ 8) Opp. 288. 
um sich von dem Verdacht frei zu machen ${ }^{1}$ ). Eine gewisise Aehnlichkeit besitzt mit diesem Ordal das Gottesurtheil des gew'eiliteri Bissens, judicium offae, das wohl bereits dem heidnischen Réoh't eigen war, jedenfalls durch das alttestamentarische Vorbild auch kïrehTiche Sanktion érlangt hatte ${ }^{2}$ ). Deshalb lässt auch Agobard dies Ordal ganz unネngefochter. Der gleiche Grund erklärt sein Schweigen über das Losordal, das ebenfalls in mehreren Bestimmungen des alten Testaments seine Rechtfertigung zu besitzen schien ${ }^{3}$ ), wenngleich es auch wiederholt gerade von kirchlicher Seite heftigen Anfeindungen ausgesetzt war ${ }^{4}$ ).

Die fragliche Stelle, in der Agobard die kirchlich zu missbilligenden Ordalien anführt, hat folgenden Wortlaut ${ }^{5}$ ): Neque sanctus et innocens vir David persecutori suo Saul dicerèt: „Si Deus te 'incitat contra me odoretur sacrificio etc." Séd potius diceret: " Mitte únum de tuis qui congrediatur mecum singulari certamine et probét me reum tibi esse si occiderit" aut certe: "Jube ferrum vel aquas calefieri, quas manibus illaesus attrectem: aut constitue ${ }^{6}$ ) cruces ad quas stans immobilis perseverem. " Offenbar soll hier eine erschöpfende Aufzählung gegeben sein, wie sie der Plan der Arbeit, díe sich gegen alle kirchlich unzulässigen Gottesurtheile kehrt, durchaus vèrlangt. Dazu stimmt auch der Folgesatz: Cum autem nihil tále lex divina vel etiam humana sanxerit ${ }^{7}$ ), et vani homines nominent ista judicium Dei. Also gerade die nacherwähnten Formen werden als die fälschlich unter die Gottesurtheile gezählten bezeichnet.

Agobard nennt demnach nur vier Arten: den Zweikampf, das Ordal des heissen Eisens, den Kesselfang und die Kreuzprobe. Unter Berücksichtigung des schon erwähnten Umstandes, dass er das Ordal des Probebissens und des Loses von seinem Standpunkt aus fortlassen musste, ergiebt sich hiernach für das fränkische Recht seiner Zeit die Existenz von sechs Gottesurtheilen, unter denen sich der angebliche Flammengriff nicht befindet.

Die Annahme, dass Agobards Aufzählung erschöpfend sei, scheint allerdings damit widerlegt zu sein, dass sie des Wasserordals und des Bahrgerichts nicht gedenkt, von denen das erstere zweifellos; das

1) Mos. 5, 12-31. 2) Wilda 482.

8) Joв. 7, 14 fg., 1 Sam. 14, 37 fg., Sp. 16, 33. 18, 18.

4) Wilda 480. Brunner 2, 414.

5) Opp. $288 . \quad$ o) Constituo ist Druckfehler.

7) Das ist nicht ganz richtig. Die weltliche Gesetzgebung hatte die Gottesurtheile durchaus gebilligt. 
zweite wenigstens nach Brunner ${ }^{1}$ ) ebenfalls schon in dieser Periode in Uebung standen.

Allein das Wasserordal war unter Ludwig dem Frommen 829 modificirt oder sogar verboten worden 2). Agobards Schrift, die wohl orst nach diesem Zeitpunkt verfasst ist - bis dahin dürfte seine schriftstellerische Thätigkeit von der Vertheidigung seiner persönlichen Verhältnisse in Anspruch genommen worden sein ${ }^{3}$ ) - hatte daher keine Veranlassung, sich auch gegen dies Gottesurtheil auszusprechen, das sich in der Praxis allerdings wieder rasch einbürgerte. Das Bahrgericht endlich kommt erst im späteren Mittelalter als rechtliche Institution vor, wenngleich es auch schon vorher in der Volkssitte geherrscht haben mag ${ }^{4}$ ). Jedenfalls war seine gerichtliche Anwendung unserer Periode fremd; also auch hier erklärt sich das Schweigen Agobards, ohne die Vollständigkeit seiner Aufzählung in Frage zu stellen.

Vermissen könnte man etwa das Ueberschreiten des brennenden Holzstosses, wodurch Thietberga, die Gemahlin Lothars II. ihre Unschuld dargethan haben soll. Diese Nachricht entstammt jedoch erst dem späten Mittelalter; zeitgenössische Berichterstatter nennen andere dabei angewendete und bereits erwähnte Ordalien ${ }^{5}$ ).

Bern.

Otto 0 pet.

Zur Chronologie der Päpste. Beiträge zu der höchst unsichern Chronologie der Päpste des 10. u. 11. Jahrhunderts liefern die römischen Privaturkunden der Zeit, deren ich eine Anzahl in dem Archive von $\mathrm{S}^{2}$ Maria in Via Lata eiusehen und abschreiben durfte. Die Datirung dieser Urkunden darf überhaupt und speciell, was die Papstjahre angeht, als sehr zuverlässig angesehen werden, da die Verfasser und Schreiber der Urkunden tabelliones urbis Tromae und scriniarii sanctae Romanae ecclesiae sind. Die Reihenfolge der chronologischen Merkmale in der Datirung ist in der Regel: 1. Papstjahr; 2. Kaiserjahr (wenn ein Kaiser vorhanden ist); 3. Indiction; 4. Monat; 5. Tag. Da wir die Indiction berechnen können und das Kaiserjuhr durch den Tag der Krönung bestimmt ist, kann man auf den Beginn des Papstjahres zurückschliessen.

1) Deutsche Rechtsgeschichte 2, 411.

2) 1. c. Anm. 58, 59 .

8) Seine Streitigkeiten mit den Juden fallen in die Jahre 822-825. Aronius, Regesten zur Geschichte der Juden $33 \mathrm{fg}$., ur. 84-97.

i) Lehmann, Das Bahrgericht (Abhandlungen zum 70. Geburtstag Konrad von Maurere) $24 . \quad$ s) Grimm 912. 